\title{
Study of the Visual Outcome and Complication of Femtosecond Lasik
}

\author{
Anand Shekhar Handi ${ }^{1}$, Prashanthkumar Narayan Achar², Mohammad Sameerudeen Moosa Beary ${ }^{3}$ \\ ${ }^{1}$ Department of Ophthalmology, National Institute of Ophthalmology Hospital, Pune, India. ${ }^{2}$ Department of \\ Ophthalmology, Srinivas Institute of Medical Sciences \& RC, Mangalore, Karnataka, India. ${ }^{3}$ Department of \\ Ophthalmology, Indiana Hospital, Mangalore, Karnataka, India.
}

\section{ABSTRACT}

\section{BACKGROUND}

Femtosecond lasers have changed refractive surgery in the last 9 years since the market release of the IntraLase Femtosecond Laser (Abbott Medical Optics, IL, USA) in 2001. In refractive surgery, a promising treatment modality using only the femtosecond laser (no excimer laser involved) is called FLEx. In this procedure, the femtosecond laser is used to cut a lenticule of corneal stroma, instead of an excimer laser ablating this same tissue. With this in mind we tried to assess the visual outcome and complication of femtosecond Lasik at the tertiary eye care centre.

\section{METHODS}

A case series study was conducted at tertiary eye care institute. Study participants were in the age group of 18 to 40 years of age attending the outpatient department suffering from difficulty in vision due to refractive error like myopia, hyperopia, and astigmatism. This study included 101 patients with the refractive error undergoing femtosecond Lasik surgery. Follow up was be performed after a period of 2 days, 5 days, 2 weeks, 1 month of surgery.

\section{RESULTS}

In this study, we found that the majority of patients undergoing femtosecond Lasik were in the age group of 20 - 24 years. In 200 eyes examined preoperatively LogMAR visual acuity has a mean variation of 0.19 with SD 0.08 . Un aided post-operative day 2 vision revealed excellent outcome when compared to preop vision with $p(0.001)$. It was statistically significant. Consistent results sprang up during the study period in the subsequent post op follow up on $5^{\text {th }}$ day, 2 weeks and 1 month.

\section{CONCLUSIONS}

Femtosecond Lasik had excellent visual outcomes and lesser complications.
Corresponding Author:

Dr. Prashanthkumar Achar, Department of Ophthalmology, Karwar Institute of Medical Sciences, Karwar-581301, Karnataka, India. E-mail: pnachar2012@gmail.com

DOI: $10.14260 / \mathrm{jemds} / 2020 / 814$

How to Cite This Article:

Handi AS, Achar PN, Beary MSM. Study of the visual outcome and complication of femtosecond lasik. J Evolution Med Dent Sci 2020;9(49):3706-3710,

$10.14260 /$ jemds/2020/814

Submission 27-04-2020,

Peer Review 15-10-2020,

Acceptance 21-10-2020,

Published 07-12-2020.

Copyright ( 92020 Anand Shekhar Handi et al. This is an open access article distributed under Creative Commons Attribution License [Attribution 4.0 International (CC $B Y 4.0)]$

\section{KEY WORDS}

Visual Complication, Femtosecond Lasik 


\section{BACKGROUND}

Femtosecond lasers have changed refractive surgery in the last 9 years since the market release of the IntraLase Femtosecond Laser (Abbott Medical Optics, IL, USA) in 2001. The bladeless flap creation rapidly gained popularity because of its promised increased safety ${ }^{1}$, fast recovery and excellent results. Nowadays, the majority of high-volume refractive surgery centres in the world uses a femtosecond laser to create the flap. All commercially available devices use a near infrared femtosecond laser with a wavelength of approximately 1053 $\mathrm{nm}$. Despite the fact that the neodymium-doped yttrium aluminium garnet and femtosecond lasers have very similar wavelengths. The ultra-short duration of the pulses (10-9 vs. 10-15) in the latter causes significantly less damage in the collateral tissue. ${ }^{2}$ The main technical specifications that play a role in the femtosecond laser are Laser pulse repetition rate; Spot size; Pulse energy; Pulse pattern. There is an inverse relationship between the laser pulse duration and the energy required in ${ }^{3}$ each pulse to generate the optical breakdown. A shorter pulse (200-500 fs) needs lower energy to achieve the threshold of photo disruption than a longer pulse (500-1300 fs). The numerical aperture (NA) of the lens influences the laser spot in terms of diameter and volume. A higher NA focuses the beam with less dispersion and is the reason why higher NA devices use lower energy. It is also suggested that a higher NA increases the depth accuracy and overall precision of the lamellar cut.

The first devices operated with a low $\mathrm{KHz}$ repetition rate (15 KHz - first IntraLase model) and needed a higher energy to photo dissection. Newer devices (even the newer highenergy devices such as IntraLase $150 \mathrm{KHz}$ ) intend to increase the repetition rate, which makes the procedure duration shorter and uses lower energy with an intention of diminishing the inflammation. In addition, the spot size and separation can be lowered in higher repetition rates to produce smoother surface cuts without increasing the time of the procedure. In summary, the ideal device would include a high repetition rate, small spot size and low energy per pulse two main pulse patterns are used in commercially available corneal cutting devices: raster and spiral. The first involves pulses that are applied in a linear pattern, starting at the hinge area, passing through the centre of the cornea and finally extending to the opposite edge. The spiral pattern is applied when the laser pulses begin centrally and expand centrifugally out to the periphery (centripetally can also be used). Most devices use the raster pattern, which was found to produce a smoother stromal bed in the IntraLase machine. Visumax (Carl Zeiss Meditec AG, Jena, Germany) uses the spiral pattern. Rainbow glare is an optical effect due to light scattering from the perfect array of laser spots remaining on the back surface of the flap. It can create a spectral pattern whose visual impact is clinically inconsequential in the majority of patients. Both of these situations are predominately related to earlier, femtosecond laser devices with higher raster energy and lower numerical aperture optics. The IntraLase was the first device and set the standards regarding energy delivered and geometry of cuts. The IntraLase had the strategic advantage of being the first, and achieved significant market penetration, so that it is number one in the market share.

In refractive surgery, a promising treatment modality using only the femtosecond laser (no excimer laser involved) ${ }^{4}$ is called FLEx. In this procedure, the femtosecond laser is used to cut a lenticule of corneal stroma, instead of an excimer laser ablating this same tissue. The refractive outcomes are still not as good as the excimer laser treatments, but there is room for improvement. The theoretical advantage over the standard procedure is that it is faster, has no need of two different lasers and less energy is applied. In addition, in excimer laser ablation we observe a reduction in laser efficiency in the periphery of the cornea, yielding results that differ from that expected with wave front-guided and optimized treatments. This would not be a problem with the femtosecond laser-cut lenticules, with the first results showing a large prelate treatment zone, and with less induction of high-order aberrations. ${ }^{5}$

With this in mind we tried to assess the visual outcome and complication of femtosecond Lasik at the tertiary eye care centre.

\section{METHODS}

A case series study was conceived and planned at the National Institute of Ophthalmology Hospital, Pune, Maharashtra, a comprehensive eye care centre which acts as a tertiary unit for eye care in western Maharashtra. Following clearance from the Institutional Scientific Committee and Ethical Committee to carry out the study the study was initiated. The patients attending the outpatient department of National Institute of Ophthalmology Hospital, Pune, Maharashtra, between June 2018 to May 2019 were chosen based on a pre-defined criterion mentioned below.

\section{Inclusion Criteria}

- Patients with refractive error.

- Patients with stable refraction for 1 year.

- Patients from either sex were included in the study.

- Patient within age group of 18 to 40 yrs.

- Patients with no media opacity or retinal pathology or gross ocular disease, Central corneal thickness minimum of 500 micrometres.

- Patients having refractive error falling within the range mentioned in the below table were included in the study.

\section{Refractive Error Type Range}

- Myopia - 1.00 Ds to - 12.00 Ds.

- Hypermetropia + 1.00 Ds to + 6.00 Ds.

- Astigmatism +1.00 Ds to + 5.00 Ds.

\section{Exclusion Criteria}

- Patients with retinal pathology other than MRD and low vision due to other cause other than refractive error, Patient who has preoperative inflammatory ocular disease or glaucoma, patient who has media opacification and cataract, patient with pre-existing corneal disease (keratoconus, opacity),

- Patients with moderate to severe dry eyes, previous intraocular surgery / trauma to same eye.

- Patient who doesn't follow up, patient who doesn't understand implication of protocol. 


\section{Data Collection}

The patients who met the criteria were chosen for the study and were given detailed information of the study. 200 eyes of 101 patients who gave informed written consent were chosen by universal sampling method to be included in the study. All patients underwent a detailed slit lamp examination using Appaswamy machine to rule out dry eye, any conjunctival pathology, corneal diseases like keratoconus or another degenerative, the intraocular pressure is measured using NCT (Keeler Plusair). The pupil morphology and reaction and corneal topography and pachymetry was done using Pentacam (Sirius) A detailed fundus examination was done by retina consultant using IDOby volks $20 \mathrm{D}$ to note any pathology like MRD, WWOP (White With-Out Pressure), Lattice degeneration so that if any patient found with the lattice degeneration or so is preoperatively treated with Barrage laser. Once the patient was fit for the surgery, they were given an appointment. All the cases underwent femtosecond Lasik surgery for difficulty in vision as a result of refractive error like myopia, hyperopia, and astigmatism. The patients were evaluated by Autorefractometer (Tomey) to take reading. Follow up was performed following femtosecond Lasik surgery on postoperative day-2, day-5, day-14 day (2 weeks) and day-20 (1 month). The follow up visits included-Visual acuity testing using log mar vision chart, IOP (Intra-Ocular Pressure) measurement, the condition of cornea assessment and documented on each post-operative visit with the slit lamp examination. The results of the studies were analysed based on the demographic details pre and post-operative visual outcome, intraocular pressure, and were presented in appropriate charts, tables, graphs and figures and statistically interpreted.

\section{Statistical Analysis}

The data on categorical variables is shown as n (\% of cases) and the data on quantitative variables (LogMAR Vision, IOP etc.) is presented as Mean \pm Standard Deviation (SD) along with range ( $\min -\max$ ). The pre-op and post-op comparisons of quantitative variables is done using paired ' $t$ ' test, after confirming the underlying normality assumption of difference of variables measured. The post-op day 2 and post-op day 5, 2week and 1-month comparisons of cornea status are done using paired " $t$ " test. The entire data was entered and cleaned in MS Excel before it was statistically analysed in SPSS. All the results are shown in tabular as well as graphical format to visualise the statistically significant difference more clearly. The p-values less than 0.05 are considered to be statistically significant. All the hypotheses data was analysed statistically using Statistical Package for Social Sciences (SPSS Ver. 16.0, Inc. Chicago, USA) for MS Windows.

\section{RESULTS}

Majority of the sample population i.e., $75 \%$ belonged to age group between 20 - 29 years. Males formed $44 \%$ of sample and 56 / 5 of them were females (Table 1). $86 \%$ of eyes had preoperatively normal anterior segment findings. Exophoria existed in the $11 \%$ of the eyes studied. For $74.5 \%$ of eyes with the refractive error were corrected with the spectacles. In
Table 2 we can see that $25.5 \%$ of eyes had previously contact lens application to rectify the refractive error.

\begin{tabular}{|c|c|c|c|}
\hline \multicolumn{2}{|c|}{ Characteristics } & No. of Cases $(n=101)$ & Percentage of Cases \\
\hline \multicolumn{4}{|c|}{ Age (years) } \\
\hline \multicolumn{2}{|r|}{$<20$} & 6 & 5.9 \\
\hline \multicolumn{2}{|c|}{$20-24$} & 45 & 44.6 \\
\hline \multicolumn{2}{|c|}{$25-29$} & 31 & 30.7 \\
\hline \multirow{2}{*}{\multicolumn{2}{|c|}{$>=30$}} & 19 & 18.8 \\
\hline & & Sex & \\
\hline \multicolumn{2}{|c|}{ Male } & 44 & 43.6 \\
\hline \multicolumn{2}{|c|}{ Female } & 57 & 56.4 \\
\hline \multicolumn{4}{|c|}{ Demographic Distribution among the Operated Cases } \\
\hline \multicolumn{2}{|c|}{ Characteristics } & No. of Eyes $(n=200)$ & Percentage of Eyes \\
\hline \multirow{5}{*}{ Laterality } & Right Eye & 101 & 50.5 \\
\hline & Left Eye & 99 & 49.5 \\
\hline & Normal & 65 & 32.5 \\
\hline & MRD & 122 & 61 \\
\hline & PVD & 2 & 1 \\
\hline \multirow[t]{3}{*}{ Retina } & WWOP & 5 & 2.5 \\
\hline & $\begin{array}{l}\text { Pre-op Barrage } \\
\text { Laser }\end{array}$ & 5 & 2.5 \\
\hline & Lasered Retina & 1 & 0.5 \\
\hline \multirow{3}{*}{ Contact Lens } & Yes & 51 & 25.5 \\
\hline & No & 149 & 74.5 \\
\hline & Normal & 172 & 86 \\
\hline \multirow{2}{*}{ Ant. Segment } & Exophoria & 22 & 11 \\
\hline & ADS & 6 & 3 \\
\hline \multicolumn{4}{|c|}{ Table 1. Distribution of Baseline Characteristics } \\
\hline
\end{tabular}

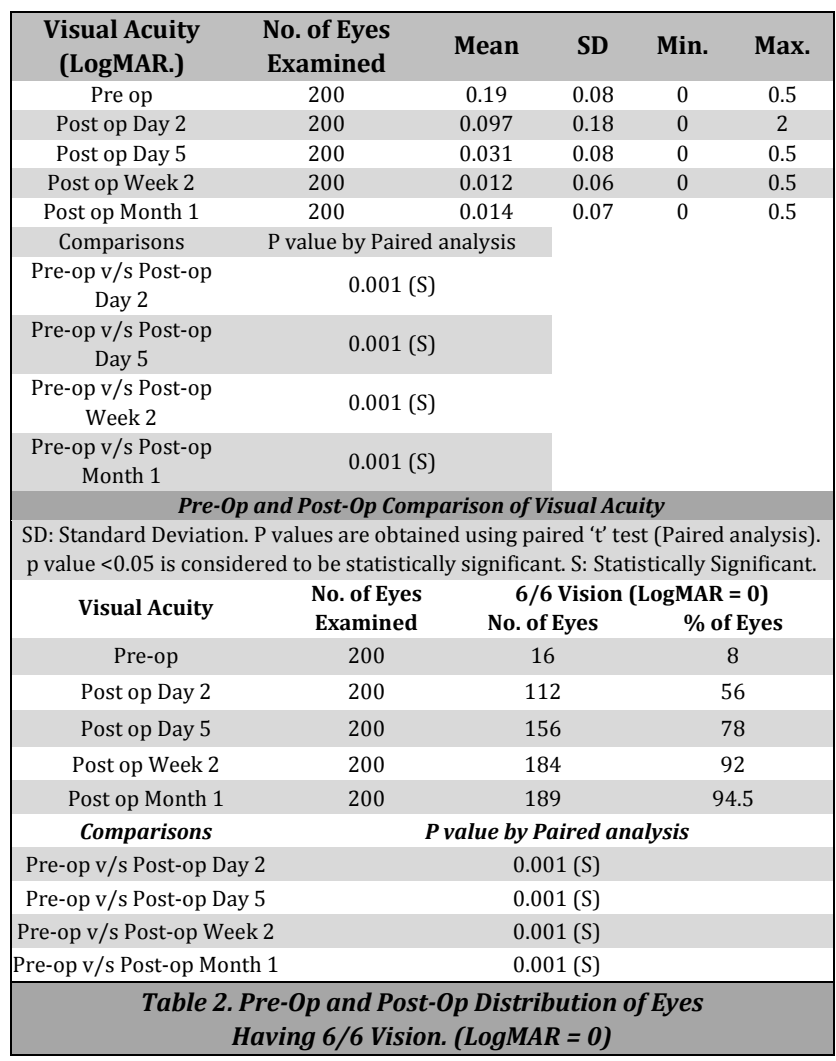

\begin{tabular}{|ccc|}
\hline Complications & No. Eyes (n= 200) & Percentage of Eyes (\%) \\
Nil & 153 & 76.5 \\
DLK & 27 & 13.5 \\
(Diffuse Lamellar Keratitis) & 20 & 10 \\
Dry eyes & 200 & 100 \\
Total & No. Eyes (n=200) & Percentage of Eyes (\%) \\
List of Post-Op Complication in Early Post-Operative Period (Day 2 $\mathbf{~ W e e k s )}$ \\
Complications & 196 & 98 \\
Nil & 4 & 2 \\
Dry eyes & 200 & 100 \\
\hline Total & & \\
\hline Table 3. Complication at the End of Post Op FUP (1 Month) \\
\hline
\end{tabular}


Pre op fundus evaluation of 32.5. \% of eyes revealed normal findings, Myopic retinal degeneration existed in $61.0 \%$ eyes preoperatively. Preoperatively barrage laser treatment was given in $2.5 \%$ of eyes.

In Table 3a we can see that the average LogMAR Visual acuity significantly improved at day 2 , day 5 , week 2 and 1 month follow-up compared to pre-op LogMAR Visual acuity ( $\mathrm{p}$ $<0.001$ ). Table $3 \mathrm{~b}$ shows significantly higher proportion of eyes achieved 6 / 6 vision at day 2, day 5, week 2- and 1-month post-op follow-up compared to Pre-op vision ( $p<0.001$ ). Initial post-op follow-up period (day $2-2$ weeks) $76.5 \%$ eyes following post femtosecond Lasik surgery had no complication. Diffuse lamellar keratitis was noted in $13.5 \%$. Of eyes out of 200 eyes studied. At the end of 1 month $98 \%$ of eyes had no complication. (Table $4 \mathrm{a}$ and $4 \mathrm{~b}$ ).

\section{DISCUSSION}

Femtosecond Lasik surgery is very popular surgery commonly known as bladeless Lasik surgery among common people. It gives better quality of unaided vision by giving them freedom from spectacle or contact lens in near future. It also emerged as most efficient surgery in recent decades. With more safety, precision, accuracy, and finally better visual outcome. It can be recommended as a good surgical option for patient undergoing refractive surgeries.

A baseline data from our study showed females outnumbered males in undergoing femtosecond Lasik surgery. This demographic data correlates with the other studies.6,7 In present study, patients undergoing femtosecond Lasik were in the age group of 18 - 40 years, which was chosen as a criterion. In reference to study Zhang J et al $^{7}$ where age group from 18 to 48 years was taken. In our study majority of patients undergoing femtosecond Lasik were in the age group of 20 24 years. (44.6)

Un aided post operatively day 2 examination revealed visual outcome was excellent when compared to pre op vision with $p(0.001)$ stating it to be statistically significant. Note: As it was difficult to find study exclusively done on IntraLase Lasik and compare to our study, so IntraLase Lasik outcome from various studies have been compared.

In comparison to other studies the visual outcome of our studies was good. When post op day 1 vision of Daniel et al is $45 \%$. But our study vision post op day 2 is $56 \%$. Finally, 1 month post op UCVA (UN-Corrected Visual Acuity) is $94 \%$. As compared to UCVA of Daniel et al which is $67 \%$. Findings of Steven C et al are good (68\%) as compared to our study group (56\%). But final outcome at the end of 1-month UCVA of our study excelled far with $94 \%$. As compared to Steven C et al. (85\%). As compared to Edward et al the results of our study are almost same. i.e. (1-month post op UCVA of both studies are $94 \%$ ). Finally comparing with Charls C et al. post op day 1 UCVA which is (60\%) is good as compared to our study day 2 (56\%).

Complications of initial post op follow up period (Day $2-2$ weeks), $76.5 \%$ eyes following post femtosecond Lasik surgery had no complication. Diffuse lamellar keratitis was noted in $13.5 \%$ of eyes out of 200 eyes studied which closely matches with the Choe $\mathrm{CH}$, Guss C e tal. $1220 \%$ of eyes had dry eyes in initial post-operative period but they were treated with the lubricating eye drops. Finally, reducing the dry eyes in subsequent post op follow ups. In Late post op follow up period ( 1 month) $98 \%$ of eyes had no complication at the end of 1-month post op visit. The results of our studies are similar to that. ${ }^{12}$ Dry eyes were noted in only $2 \%$ of eyes at the end of post op 1 month follow up.

\begin{tabular}{|c|c|c|}
\hline \multicolumn{2}{|c|}{$\begin{array}{c}\text { Our study Post Op Vision (\%) } \\
\{200\} \text { Eyes UCVA }\end{array}$} & $\begin{array}{c}\text { Daniel et al Post Op Vision (\%) } \\
\{102\} \text { Eyes UCVA }\end{array}$ \\
\hline Day 2 & 56 & 45 (day 1 ) \\
\hline Day 5 & 78 & 43 (1 week) \\
\hline 2nd week & 92 & --- \\
\hline 1-month & 94 & $67(1$ month) \\
\hline \multicolumn{3}{|c|}{ Our Study Vs Daniel et al ${ }^{8}$} \\
\hline \multicolumn{2}{|c|}{$\begin{array}{c}\text { Our Study Post Op Vision (\%) } \\
\{200\} \text { UCVA }\end{array}$} & $\begin{array}{c}\text { Steven C et al Post Op Vision (\%) } \\
\{300\} \text { Eyes UCVA }\end{array}$ \\
\hline Day 2 & 56 & 68 (Day 1) \\
\hline Day 5 & 78 & --- \\
\hline $2^{\text {nd }}$ week & 92 & --- \\
\hline 1-month & 94 & 85(1 month) \\
\hline \multicolumn{3}{|c|}{ Our Study Vs Steven C et al ${ }^{9}$} \\
\hline \multicolumn{2}{|c|}{$\begin{array}{c}\text { Our study Post Op Vision (\%) } \\
\{200\} \text { Eyes UCVA }\end{array}$} & $\begin{array}{c}\text { Edward E et al Post Op Vision (\%) } \\
\{94\} \text { eyes UCVA }\end{array}$ \\
\hline Day 2 & 56 & 54 (day 1) \\
\hline Day 5 & 78 & 79 (1 week) \\
\hline 2nd week & 92 & ---- \\
\hline 1 month & 94 & 94 (1 month) \\
\hline \multicolumn{3}{|c|}{ Our Study Vs Edward et al ${ }^{10}$} \\
\hline \multicolumn{2}{|c|}{$\begin{array}{c}\text { Our Study Post Op Vision (\%) }\{200\} \\
\text { Eyes }\end{array}$} & $\begin{array}{c}\text { Charls C et al Post Op Vision (\%) } \\
\{1020\} \text { Eyes }\end{array}$ \\
\hline Day 2 & 56 & 60 (day1) \\
\hline \multicolumn{3}{|c|}{ Our Study Vs Charls C et al11 } \\
\hline & & \\
\hline
\end{tabular}

\section{CONCLUSIONS}

Refractive error is the $2^{\text {nd }}$ major cause of impaired vision. Patients with refractive error can be corrected by many methods. But femtosecond Lasik is safe, accurate, is most feasible and more precise in current days. Making the femtosecond Lasik surgery to be recommended as the procedure of choice in refractive surgery. Post femtosecond Lasik complication are very less as noted in the above study. Making it safer procedure. In giving freedom from glasses to the patients and helping them to achieve better quality of vision.

Data sharing statement provided by the authors is available with the full text of this article at jemds.com.

Financial or other competing interests: None.

Disclosure forms provided by the authors are available with the full text of this article at jemds.com.

\section{REFERENCES}

[1] Montés-Micó R, Rodríguez-Galietero A, Alió JL. Femtosecond laser versus mechanical keratome LASIK for myopia. Ophthalmology 2007;114(1):62-8.

[2] Faktorovich E. Femtodynamics. $1^{\text {st }}$ edn. NJ, USA: Slack Incorporated, 2009.

[3] Vogel A, Busch S, Jungnickel K, et al. Mechanisms of intraocular photodisruption with picosecond and nanosecond laser pulses. Laser Surg Med 1994;15(1):3243.

[4] Ruiz LA, Cepeda LM, Fuentes VC. Intrastromal correction 
of presbyopia using a femtosecond laser system. J Refract Surg 2009;25(10):847-54.

[5] Blum M, Kunert K, Schröder M, et al. Femtosecond lenticule extraction for the correction of myopia: preliminary 6-month results. Graefes Arch Clin Exp Ophthalmol 2010;248(7):1019-27.

[6] Baily C, GráinneBrosnan RN, O’Keefe M. Femtosecond laser, mechanical keratome, LASIK. J Emmetropia 2012;3:7381.

[7] Zhang J, Zhang SS, Yu Q, et al. Comparison of corneal flap thickness using a FS200 femtosecond laser and a moria SBK microkeratome. Int J Ophtholmol 2014;7(2):273-7.

[8] Durrie DS, Kezirian GM. Femtosecond laser versus mechanical keratome flaps in wavefront-guided laser in situ keratomileusis: a prospective contralateral eye study. J of Cataract and Refractive Surg 2005;31(1):120-6.

[9] Schallhorn SC. European Society of Cataract \& Refractive Surgeons, Paris, France: September 21, 2004. Lisbon, Portugal: September 13, 2005.

[10] Manche EE. The American Academy of Ophthalmology, Chicago, IL: October 17, 2005. European Society of Cataract and Refractive Surgeons, Lisbon, Portugal: September 12, 2005.

[11] Manger CC 3rd. The IntraLase advantage. Ophthalmology Management, February 2004.

[12] Faktorovich EG. Joint Meeting of the American Academy of Ophthalmology \& The International Societty Refractive Surgery, Chicago, IL: October 14, 2005. 